\title{
Microbial transformation of crop residues into a nutritionally enriched substrate and its potential application in livestock feed
}

\author{
Ravindra H. Patil ${ }^{1}$ (D . Mohini P. Patil ${ }^{1}$ - Vijay L. Maheshwari ${ }^{2}$
}

Received: 30 November 2019 / Accepted: 22 May 2020 / Published online: 29 May 2020

(c) Springer Nature Switzerland AG 2020

\begin{abstract}
Bioconversion of three different agro-residues (groundnut shells, pigeon pea husk and wheat straw) was studied using endophytic fungi with a view to increasing the nutritive value and to evaluate its feasibility as poultry feed. An endophytic fungal isolate obtained from Celastrus paniculatus, effectively biotransformed selected agro-residues in solid state fermentation. After 21 days incubation, isolate CPL-1 significantly altered the nutritional values of all tested agroresidues. Cellulose, hemicellulose, and lignin content were significantly reduced $(P<0.05)$ whereas, total carbohydrates were significantly increased in the biotransformed waste as compared to untreated residues. Of the three agro-residues studied, the groundnut shells were found to have maximum carbohydrate content $(13.92 \pm 0.7 \mathrm{~g} / 100 \mathrm{~g})$ after the treatment. Similarly, the total crude protein and total nitrogen contents of the treated waste were also significantly improved $(P<0.05)$ as a function of treatment with the isolate CPL- 1 with their highest contents $(24.95 \pm 1.4$ and $15.53 \pm 1.2 \mathrm{~g} / 100$ $\mathrm{g}$, respectively) recorded in the treated groundnut shells. The isolate CPL-1 was identified as Colletotrichum spp. based on the morphology. The tannins and phytate contents were found to be significantly lower $(P<0.05)$ in the processed wastes. Application of treated agro-residues in poultry diets revealed that the biotransformed groundnut shells and pigeon pea waste can be added up to 20 and $10 \%$, respectively to the commercial poultry diet used in the study without any adverse effects. The results showed that the treated residues of groundnut shells can be used as a partial substitute to the conventional poultry diets as they are rich in enzyme phytase and other nutrients and have good digestibility.
\end{abstract}

Keywords Bioconversion · Agro-residues · Endophytic fungi · Crude protein · Poultry diet

\section{Introduction}

Feed is the most important factor in the poultry business which constitutes around $70 \%$ of the total production cost [1]. A number of ingredients are used to formulate the poultry diet. It mainly uses maize and soybean meal as the carbon and protein source, respectively. Several countries use other grains such as wheat, sorghum, canola and sunflower meal as well as animal-derived protein ingredients like fish and meat meal [2]. Mineral supplements play a vital role in the development of poultry. Poultry, being the monogastric animal, cannot fully assimilate the inorganic supplements which are provided in the form of calcium and phosphorus supplements that includes dicalcium phosphate, rock phosphate and bone meal [3]. The increasing cost and decreasing feed production are the major hurdles in the progress of poultry industry in the developing countries. Moreover, diversion of food grains such as maize and sorghum from feed market to ethanol production has dramatically increased their cost globally $[4,5]$. Therefore, there is the urgent need to use alternative feedstuffs and look into the possibilities of bioconversion of agro-residues into feed in a sustainable way. Globally, 140 billion metric tons of lignocellulose biomass

$\triangle$ Ravindra H. Patil, ravi_nmu@yahoo.co.in | 'Department of Microbiology and Biotechnology, R. C. Patel Arts, Commerce and Science College, Shirpur 425405, India. ${ }^{2}$ Department of Biochemistry, School of Life Sciences, North Maharashtra University, Jalgaon 425001, India. 
is generated every year from agriculture. India, being the agro-based country, the huge amount agro-wastes has raised the challenge to dispose or reuse this biomass. Ministry of New and Renewable Energy (MNRE 2009), Govt. of India estimated that about $500 \mathrm{Mt}$ of crop residue is generated every year. These wastes are usually destroyed by burning that create environmental pollution [6]. Cellulose, hemicellulose, and lignin are the major polymers present in agro-residues which are used as a cheaper feed source for ruminants. However, digestibility of these polymers is the major concerns for their utilization as feed especially in a monogastric animal such as poultry. Thus, bioconversion of these complex polymers into readily available simple sugars and amino acids using endophytic fungi can significantly increase the digestibility and palatability of the agro- residues. Moreover, utilization of such waste for poultry feed cannot only reduce feed cost of the poultry farming but also reduce the environmental pollution. The conversion of lignocellulosic biomass into digestible carbohydrates is biologically feasible and can be easily adopted for bioconversion of agricultural wastes. The world over, attempts have been made for bioconversion of agricultural residues into value-added products such as pulp, animal feed, poultry feed and biofertilizer through the action proteolytic and lignin-degrading enzyme secreting microorganisms such as bacteria and fungi [7]. Although significant scientific work has been undertaken in this direction, no efforts made to develop and scale up the process for the production of valuable end products such as poultry feed using the endophytic fungi. Endophytic microorganisms multiply inside the living tissues of the plant without causing any negative effect on their host. Biotechnological potential of a number of endophytic fungi is well established [8]. In the present work, we made an attempt to isolate, identify and evaluate bioconversion potential of phytase producing endophytic fungal isolates obtained from Celastrus paniculatus. The study also evaluated the nutritional quality of the biotransformed residue and evaluated its suitability as substitute for commercially used poultry feed in broiler chicken.

\section{Materials and methods}

\subsection{Source of endophytic fungi for bioconversion studies}

Endophytic fungi were isolated from the symptomless parts of $C$. paniculatus like leaves and twigs. Plant specimens were collected from Toranmal forest, MS, India (1115 $\mathrm{m} \mathrm{AMSL}, 21.26^{\circ} \mathrm{N}, 74.09^{\circ} \mathrm{E}$ and $21.26^{\circ} \mathrm{N}, 27^{\circ} \mathrm{E}$ ) India. The mature and healthy plant specimens were brought safely to the laboratory and processed immediately to reduce the risk of contamination. Plant material was thoroughly washed with running tap water and air dried in laminar flow hood. Washed tissues of leaves, bark, and twigs were surface sterilized using $0.5 \%$ sodium hypochlorite ( $\mathrm{vol} / \mathrm{vol}$ ) for $5 \mathrm{~min}$ followed by $70 \%$ ethanol (vol/vol) for $3 \mathrm{~min}$, and finally rinsed with sterile distilled water 5 times. After surface sterilization, the samples were air dried under laminar flow hood. The samples were cut into small pieces (approximately $0.5 \mathrm{~cm} \times 0.5 \mathrm{~cm}$ ) with the sterile scalpel. A piece of inner tissue $(0.5 \mathrm{~cm} \times 0.5 \mathrm{~cm})$ was placed aseptically on the surface of sterile water agar plates and incubated at $25^{\circ} \mathrm{C}$ for $12 \mathrm{~h}$ dark and light cycle until fungal hyphae emerge out of plant tissue. After incubation of 10 to 15 days, fungal hyphae were observed. Individual hyphal tips were removed from the plate and aseptically transferred onto fresh sterile potato dextrose agar (PDA) medium supplemented with chloramphenicol $(40 \mu \mathrm{g} / \mathrm{mL})$ to avoid bacterial contamination [9]. Plates were incubated for 1 to 2 weeks at $25^{\circ} \mathrm{C}$ to obtain a pure culture of fungi. Isolated endophytic fungal cultures were designated a code based on the plant sample from where they were isolated. All the isolates were maintained by subculturing at monthly intervals and stock cultures were preserved at $4{ }^{\circ} \mathrm{C}$. From actively growing a stock culture, sub-culturing were made on fresh slants and after 7 to 8 days of incubation at $25^{\circ} \mathrm{C}$ these were used as starting a culture for identification as well as for bioconversion studies.

\subsection{Screening for phytase production}

The isolated strains of the endophytic fungi were screened for their ability to produce phytase. The screening was carried out by growing the isolated fungi on agar plates containing (g/L) Dextrose 12; $\mathrm{NH}_{4} \mathrm{NO}_{3} 4.0 ; \mathrm{MgSO}_{4} \cdot 7 \mathrm{H}_{2} \mathrm{O} 0.5$; $\mathrm{KCl} 0.5 ; \mathrm{MnSO}_{4} \cdot 7 \mathrm{H}_{2} \mathrm{O} 0.01 ; \mathrm{FeSO}_{4} \cdot 7 \mathrm{H}_{2} \mathrm{O} 0.03$ and calcium phytate 5 as a source of phosphorus (pH 5.5, after sterilization). The isolates producing clear halos were selected as phytase producers. The isolates showing halos in the primary screening were subjected to secondary screening in a shake flask culture. The sporal suspension was obtained by scrubbing the pure culture with $5 \mathrm{~mL}$ of a sterile aqueous solution of $2 \%$ tween 80 . Inoculum was developed by inoculating $5 \mathrm{~mL}$ spore suspension (approximately $10^{6}$ spores $/ \mathrm{mL}$ ) in $250 \mathrm{~mL}$ Erlenmeyer flask containing $50 \mathrm{~mL}$ seed medium containing ( $\mathrm{g} / \mathrm{L})$ glucose $20 ; \mathrm{NH}_{4} \mathrm{NO}_{3}$ 5.0; $\mathrm{MgSO}_{4} \cdot 7 \mathrm{H}_{2} \mathrm{O} 0.5 ; \mathrm{KCl} 0.5 ; \mathrm{MnSO}_{4} \cdot 7 \mathrm{H}_{2} \mathrm{O} 0.01 \mathrm{FeSO}_{4} \cdot 7 \mathrm{H}_{2} \mathrm{O}$ 0.03 and calcium phytate 5 . After the development of sufficient biomass, $10 \%$ of inoculum was transferred to production medium with the same composition. The $\mathrm{pH}$ of the media was maintained at 5.5 (after sterilization). The fermentations were carried out at $30^{\circ} \mathrm{C}$ and $150 \mathrm{rpm}$ on a rotary shaker (Steelmate Novatech, Pune, India) in a 500 $\mathrm{mL}$ shake flask containing $150 \mathrm{~mL}$ of production medium. 
At the end of the process, fungal biomass separated by centrifugation, dried and the clear supernatant was used for determining the enzyme activity.

\subsection{Bioconversion studies of various agro-wastes using phytase positive endophytic isolates in solid state fermentation (SSF)}

Different agricultural wastes were collected from nearby farms of Shirpur city. The agricultural wastes selected for the study included wheat bran, pigeon pea husk and shells of groundnut. The good quality, low-density agro-residues of the selected crops were washed thoroughly with boiling water; sun dried and pulverized using to obtain particles of 4 to $5 \mathrm{~cm}$ size. Flat glass bottles $(18 \mathrm{~cm} \times 7.5 \mathrm{~cm})$ with a volume of $350 \mathrm{~mL}$ were filled with 15 to $20 \mathrm{~g}$ of respective agro-residue and sterile distilled water was added to achieve different moisture levels $(50 \%, 60 \%, 70 \%$ and $80 \%$ ). Large scale bioconversion studies were carried out using shallow bamboo trays. The baskets were filled with pre-washed; sun dried and pulverized agro-residues of the selected crops. The solid matrix was supplemented with $2 \%$ ammonium nitrate and glucose as nitrogen and carbon source, respectively. Spore suspension $\left(10^{8}\right.$ spores per gram of solid matrix) of the bioassay positive test fungi was inoculated aseptically onto the surface of the solid matrix. The bottles were incubated at $30^{\circ} \mathrm{C}$ for 3 weeks and the growth of fungi was monitored. After 3 weeks, the bioprocess was terminated and the nutritional parameters of the processed material were determined.

\subsection{Determination of nutritive value of agro-residues before and after bioconversion}

Cellulose, hemicellulose, and lignin were determined as per the methods described by Huang et al. [25]. Total N was determined by the Kjeldahl's assay. Total protein content was determined by precipitation of washed sample with trichloracetic acid (TCA) followed by the Kjeldahl's assay. The nitrogen $(\mathrm{N})$ content was calculated from the titer value and the crude protein was obtained by multiplying the $\mathrm{N}$ content by a factor $(\mathrm{N} \times 6.25)$. A blank determination was carried out simultaneously. Tannins were determined as per the previously reported spectrophotometric method [10]. The phytate content was measured by ferric chloride assay. Standard ferric chloride precipitates phytate in acidic conditions [11]. The mineral $(\mathrm{Ca}, \mathrm{Fe}, \mathrm{Cu}$, $\mathrm{Zn}, \mathrm{Mg}$, and $\mathrm{Co}$ ) contents were determined on aliquots of the solutions of the ash by established atomic absorption spectrophotometer procedures using a Perkin-Elmer atomic absorption spectrophotometer (model 372), while $\mathrm{Na}$ and $\mathrm{K}$ were analyzed with a flame photometer. Dry weight (DW) was determined gravimetrically by drying at $105^{\circ} \mathrm{C}$ to a constant weight. Total carbohydrates and total fats were measured as per the methods of analysis of the AOAC International [12].

\subsection{Animal feed, feed preparation using fermented biomass and poultry trials}

A commercially available broiler feed (SKM Animal Feeds \& Foods Limited, TN, and India) was purchased from the local market and used as a starter and basal diet for broiler chickens. Broiler Starter-Crumble Broiler was used as the basal diet for chicks of 0 to 4 weeks of age. Whereas, Broiler Finisher-Mash Broiler was used in the young chickens from 4 to 6 weeks as per the manufacturer's recommendations. The test diets (starter and finisher) were prepared by supplementing the standard basal diet with $5 \%$ and $20 \%$ (wt/wt) of fermented biomass. The poultry trials were conducted using 600 one-day-old white broiler chicks up to 6 weeks of age at Wathoda Poultry Farm, Shirpur, MS, India. The birds were divided into 4 groups $(n=100)$. Group A birds were fed standard diets supplemented with $5 \%$ fermented biomass. Groups B and C chickens were fed the basal diet plus $10 \%$ and $20 \%$ fermented biomass, respectively. Group D served as a standard control which received normal basal and finisher diet as per manufacturer's recommendations. Birds were housed in the poultry farm and were exposed to light $24 \mathrm{~h}$ a day. The feed and water were provided ad libitum and the animals were vaccinated as per the schedule.

\section{Results}

\subsection{Endophytes isolation and preliminary screening}

Total 18 strains of endophytic fungi were isolated from the various parts of $C$. paniculatus. The isolates were designated by different codes and were maintained at $4{ }^{\circ} \mathrm{C}$. All the isolates were subjected for preliminary screening to evaluate their phytase activity and bioconversion potential in solid state bioprocess. Based on their potential in the screening experiments, 2 isolates were selected for bioconversion studies.

The phytase activity screening using calcium phosphate containing agar plates relies on the formation of clear halos as an indicator of phytase activity [13, 14]. According to the phytase screening test, one of the isolate-CPL-1, identified as Colletotrichum spp. produced extracellular phytase resulting in the formation of the clear zone on a calcium phytate-containing agar plate. Another isolate obtained from the same plant, designated as CPBA-2 and identified as Togninia spp. did not showed a significant zone of clearance though it showed considerable 
bioconversion potential. The phytase production ability of CPL-1 was also checked in liquid media. The growth of isolate-CPL-1 in phytate-containing media was found to be comparable to a negative control lacking phytate in the cultivation media. The results demonstrated that isolateCPL-1 had the ability of extracellular production of phytase when cultivated in submerged cultures. The phytase activity of isolate-CPL- 1 was found to be 0.89 and $0.24 \mathrm{U} / \mathrm{mL}$.

Figure 1 represents the colonial morphology and microscopic structure of sporangium of the two selected isolates. Isolate CPL-1 and CPBA-2, obtained from a leaf and bark tissue of $C$. paniculatas were identified as Colletotrichum spp. and Togninia spp. respectively based on their morphological characters. Therefore, based on the results of the screening studies, both the isolates-Colletotrichum spp. and Togninia spp. were selected due to stronger degradation ability of cellulosic and hemicellulose waste. Both the strains grew on tested raw agro-wastes such as wheat straw, groundnut shells, and pigeon pea waste when cultivated in SSF for 3 weeks and significantly transformed the waste residue (Fig. 2). It was observed that the moisture content of the matrix has a profound effect on the growth of the test fungi and the bioconversion of residue. The maximum growth was observed at $70 \%$ moisture level and the lowest at $50 \%$ for both the isolates. The insufficient moisture level may alter the physical properties of the solid substrate thereby affecting the growth of mycelia [15]. On the other hand, a higher than optimum moisture level reduces oxygen transfer and impedes fungal growth [16]. Both the endophytic isolates could produce large amounts of extracellular cellulase and hemicellulase in the SSF process that resulted in excellent growth on cellulosic residue.

\subsection{Nutritive value of bioprocessed residues}

The proximate composition of the agro-residues before and after fermentation using Colletotrichum spp. and Togninia spp. is shown in Tables 1 and 2, respectively. The results reveal that Colletotrichum spp. have better bioconversion activities as compared to Togninia spp. Colletotrichum spp. mediated process significantly altered the nutritional values of all tested wastes. Cellulose, hemicellulose, and lignin content were significantly reduced in the bio-transformed waste as compared to untreated residues. On the other hand, total carbohydrates were significantly increased all treated waste with groundnut being the best with maximum $\mathrm{g}$ carbohydrates $(13.92 \pm 0.7 \mathrm{~g} / 100)$. Total crude protein and $\mathrm{N}$ content of the treated waste were significantly improved. Crude protein and $\mathrm{N}$ content were the highest ( $24.95 \pm 1.4$ and $15.53 \pm 1.2$, respectively) in the bio-transformed groundnut shells using Colletotrichum
Fig. 1 Isolate CPL-1 Colletotrichum spp. (a) and structure of hyphae (b). Isolate CPBA-2 Togninia spp. (c) and structure of sporangium (d)
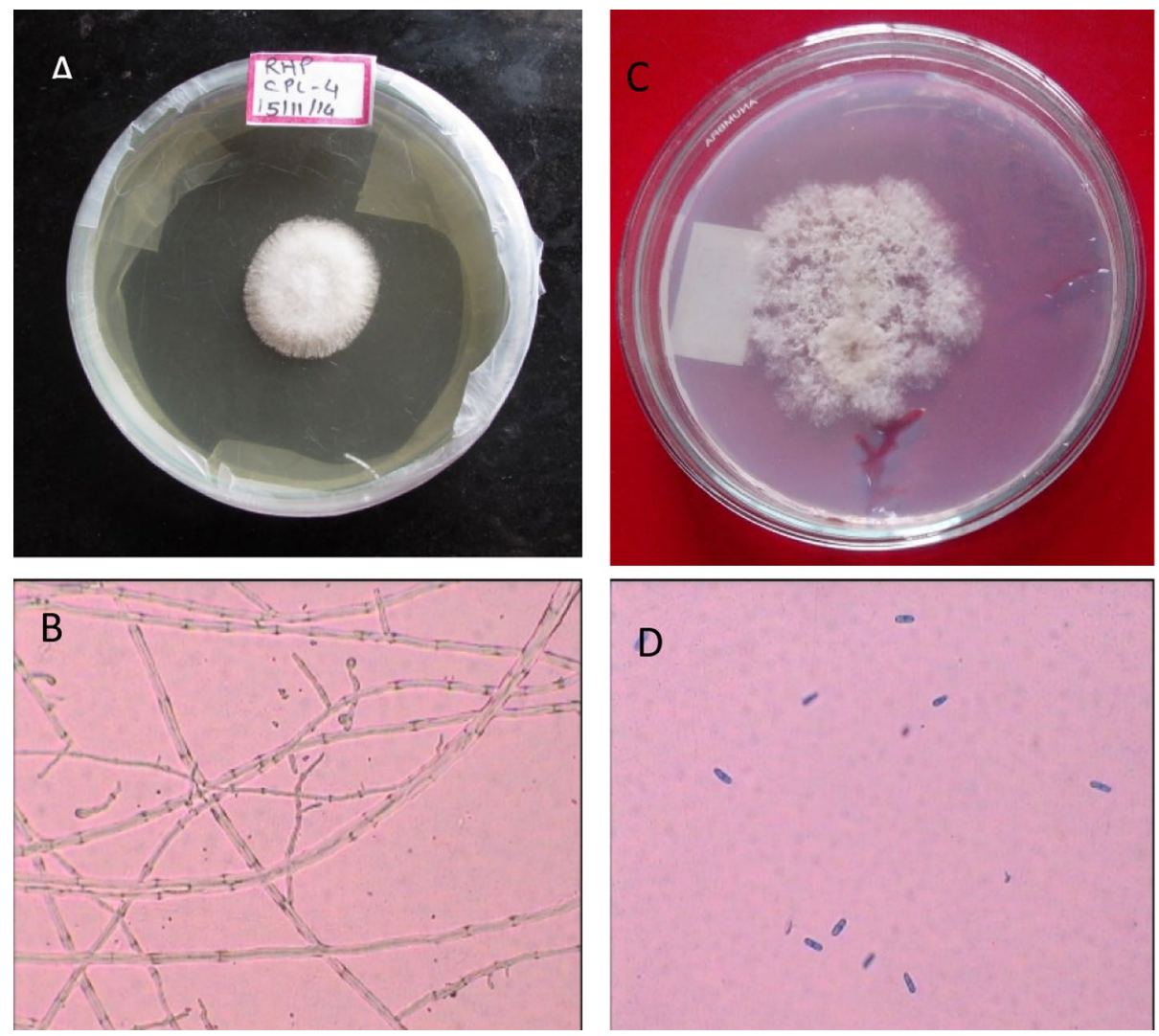

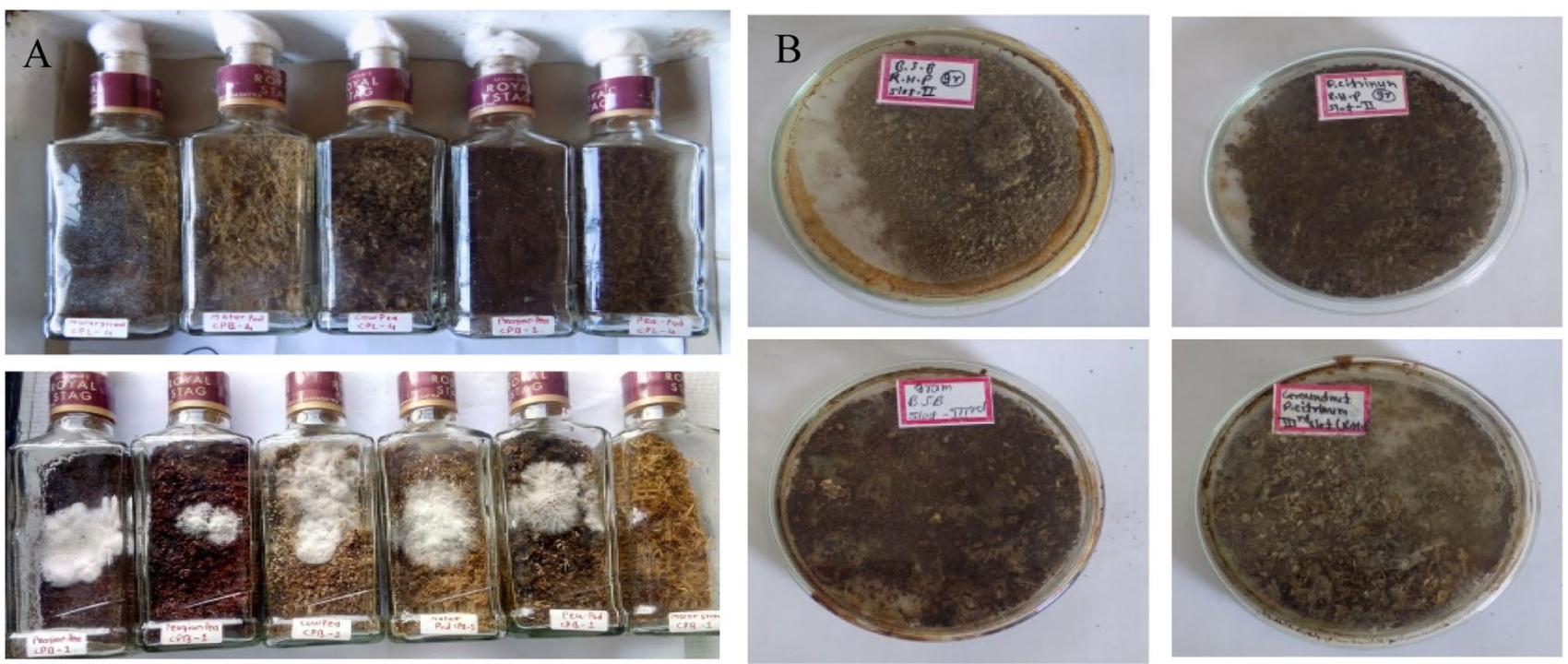

Fig. 2 Growth of endophytic isolates in various agro-wastes in solid state fermentation (a). The agro-residue after bioconversion (b)

Table 1 Proximate composition of the treated and untreated wastes on dry matter basis $(\mathrm{g} / 100 \mathrm{~g})$ using isolates CPL-1 Colletotrichum spp

\begin{tabular}{|c|c|c|c|c|c|c|}
\hline \multirow[t]{2}{*}{ Parameter } & \multicolumn{3}{|c|}{ Unfermented waste } & \multicolumn{3}{|c|}{ Fermented waste } \\
\hline & Wheat & Pigeon pea & Groundnut & Wheat & Pigeon pea & Groundnut \\
\hline Cellulose & $34.80 \pm 1.2$ & $22.65 \pm 1.4$ & $64.5 \pm 2.5$ & $20.2 \pm 1.1$ & $13.23 \pm 0.8$ & $30.2 \pm 2.1$ \\
\hline Hemicellulose & $22.36 \pm 0.9$ & $18.20 \pm 0.9$ & $11.2 \pm 0.5$ & $12.2 \pm 0.8$ & $9.90 \pm 0.6$ & $8.2 \pm 0.4$ \\
\hline Lignin & $15.58 \pm 0.7$ & $10.23 \pm 0.5$ & $12.2 \pm 0.4$ & $10.23 \pm 0.5$ & $8.2 \pm 0.4$ & $8.2 \pm 0.5$ \\
\hline Crude protein & $3.45 \pm 0.2$ & $8.41 \pm 0.5$ & $4.35 \pm 0.2$ & $10.20 \pm 0.8$ & $16.41 \pm 1.2$ & $24.95 \pm 1.4$ \\
\hline Total carbohydrates & $1.32 \pm 0.1$ & $7.32 \pm 0.3$ & $7.32 \pm 0.3$ & $10.22 \pm 0.6$ & $11.32 \pm 0.7$ & $13.92 \pm 0.7$ \\
\hline Nitrogen, \% & $6.23 \pm 0.2$ & $8.21 \pm 0.2$ & $7.23 \pm 0.3$ & $14.20 \pm 0.9$ & $13.21 \pm 1.1$ & $15.53 \pm 1.2$ \\
\hline Total fat & $2.22 \pm 0.2$ & $6.22 \pm 0.2$ & $9.32 \pm 0.4$ & $6.20 \pm 0.2$ & $9.22 \pm 0.24$ & $8.32 \pm 0.8$ \\
\hline Ash & $5.23 \pm 0.2$ & $1.95 \pm 0.2$ & $2.01 \pm 0.1$ & $5.2 \pm 0.2$ & $2.95 \pm 0.32$ & $3.06 \pm 0.7$ \\
\hline \multicolumn{7}{|c|}{ Tannin and phytate content, $\mu \mathrm{g} / 100 \mathrm{~g}$ of waste } \\
\hline Tannins & $702 \pm 10.1$ & $665 \pm 09.1$ & $454 \pm 08.1$ & $502 \pm 11.1$ & $589 \pm 09.9$ & $314 \pm 07.1$ \\
\hline Phytate & $200 \pm 07.1$ & $611 \pm 10.5$ & $465 \pm 09.1$ & $175 \pm 05.1$ & $298 \pm 05.5$ & $303 \pm 08.3$ \\
\hline
\end{tabular}

Values are means of 3 replicates \pm SD. Statistical significance between treated and untreated waste was evaluated using Student's $t$ test. $P<0.05$ was considered the statistically significant difference between treated and untreated waste spp. The tannins and phytate content was also found to be altered significantly when the waste was subjected for bioconversion using Colletotrichum spp. (Table 1). The phytate is responsible for chelating divalent cations such as $\mathrm{Ca}, \mathrm{Fe}, \mathrm{Mg}$, and $\mathrm{Zn}$, which leads to a dietary deficiency of these important minerals and ultimately retards the growth of animals. The phytate content of the fermented sample was reduced significantly as a result of microbial bioconversion.

Tannins impart a dark color to the waste whereas the phytate is known for its anti-nutrient effect as they chelate various metal ions such as $\mathrm{Ca}^{+2}, \mathrm{Mg}^{+2}, \mathrm{Fe}^{+2}$, and $\mathrm{Zn}^{+2}$. Moreover, poultry birds are unable to metabolize the phytate and therefore it has to be supplied in the form of inorganic phosphate through diet to avoid phosphate deficiency in these animals. Therefore, phosphate utilization in these animals can be improved using the feed rich with microbial phytase. The endophytic fungi in our studies produced phytase thereby reducing the phytate content and ultimately reduced its anti-nutrient effects.

\subsection{Poultry trials using supplementation of bio-transformed waste}

Based on the obtained results of the nutritional evaluation, groundnut shell waste was found to have a high nutritional value and hence the treated groundnut shells waste was selected for poultry trials. The suitability of the 
treated groundnut waste as feed was evaluated on broiler chickens (Fig. 3). The commercial poultry diet was supplemented with $5 \%, 10 \%$ and $20 \%$ of fermented biomass and its effect on body weight; feed conversion ratio and feed consumption behavior of broiler chickens were evaluated.

The data on the effect of a diet supplemented with $5 \%, 10 \%$ and $20 \%$ of fermented biomass on body weight of the chickens is shown in Table 3. No significant difference $(P<0.05)$ was observed on the body weight of test groups animals fed with different test diets. The highest body weight $(1930.3 \pm 5.89 \mathrm{~g})$ was achieved when the broilers were fed with feed supplemented with $20 \%$ fermented biomass. The body weight gain at the end of the study was even better $(1920.3 \pm 6.41 \mathrm{~g})$ than the test group fed with the standard diet. The pattern of weight gain of all test groups (groups A, B, and C) was
Table 2 Proximate composition of the fermented ground shells wastes on dry matter basis $(\mathrm{g} / 100 \mathrm{~g})$ isolate CPBA-2 Togninia spp.
Fig. 3 a Large-scale bioconversion of groundnut waste using in bamboo trays; $\mathbf{b}$ bioprocessed waste

\begin{tabular}{|c|c|c|c|c|c|c|}
\hline \multirow[t]{2}{*}{ Parameter } & \multicolumn{3}{|c|}{ Unfermented waste } & \multicolumn{3}{|c|}{ Fermented waste } \\
\hline & Wheat & Pigeon pea & Groundnut & Wheat & Pigeon pea & Groundnut \\
\hline Cellulose & $34.80 \pm 1.2$ & $22.65 \pm 1.4$ & $64.5 \pm 2.5$ & $29.2 \pm 1.6$ & $19.21 \pm 0.9$ & $41.2 \pm 3.1$ \\
\hline Hemicellulose & $22.36 \pm 0.9$ & $18.20 \pm 0.9$ & $13.2 \pm 0.6$ & $13.2 \pm 0.7$ & $10.90 \pm 0.7$ & $7.2 \pm 0.4$ \\
\hline Lignin & $15.58 \pm 0.7$ & $10.23 \pm 0.5$ & $12.2 \pm 0.4$ & $11.23 \pm 0.5$ & $7.9 \pm 0.4$ & $8.8 \pm 0.5$ \\
\hline Crude protein & $3.45 \pm 0.2$ & $8.41 \pm 0.5$ & $4.35 \pm 0.2$ & $6.45 \pm 0.4$ & $15.42 \pm 1.2$ & $09.20 \pm 0.5$ \\
\hline Total carbohydrates & $1.32 \pm 0.1$ & $7.32 \pm 0.3$ & $7.32 \pm 0.3$ & $11.22 \pm 0.8$ & $10 . .32 \pm 0.7$ & $10.42 \pm 0.9$ \\
\hline Nitrogen, \% & $6.23 \pm 0.2$ & $8.21 \pm 0.2$ & $7.23 \pm 0.3$ & $10.32 \pm 1.2$ & $11.21 \pm 1.2$ & $10.29 \pm 0.7$ \\
\hline Total fat & $2.22 \pm 0.2$ & $6.22 \pm 0.2$ & $9.32 \pm 0.4$ & $5.20 \pm 0.4$ & $7.21 \pm 0.25$ & $6.32 \pm 0.9$ \\
\hline Ash & $5.23 \pm 0.2$ & $1.95 \pm 0.2$ & $2.01 \pm 0.1$ & $1.2 \pm 0.8$ & $2.56 \pm 0.40$ & $2.26 \pm 0.8$ \\
\hline \multicolumn{7}{|c|}{ Tannin and phytate content, $\mu \mathrm{g} / 100 \mathrm{~g}$ of waste } \\
\hline Tannins & $702 \pm 10.1$ & $665 \pm 09.1$ & $454 \pm 08.1$ & $658 \pm 10.8$ & $611 \pm 09.1$ & $398 \pm 07.1$ \\
\hline Phytate & $200 \pm 07.1$ & $611 \pm 10.5$ & $465 \pm 09.1$ & $195 \pm 07.1$ & $597 \pm 11.8$ & $445 \pm 09.8$ \\
\hline
\end{tabular}

Values are means of 3 replicates $\pm S D$. Statistical significance between treated and untreated waste was evaluated using Student's $t$ test. $P<0.05$ was considered the statistically significant difference between treated and untreated waste

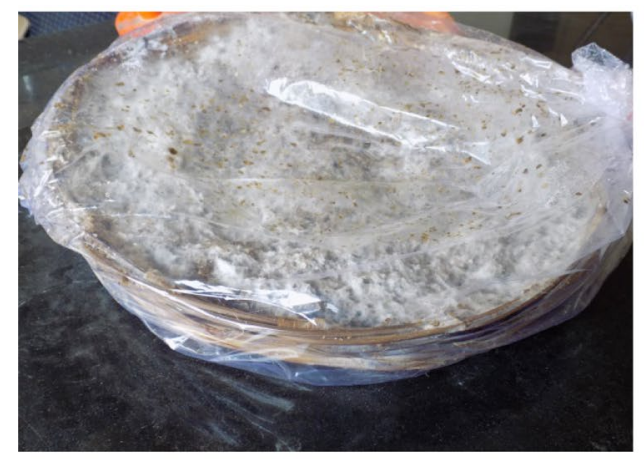

A

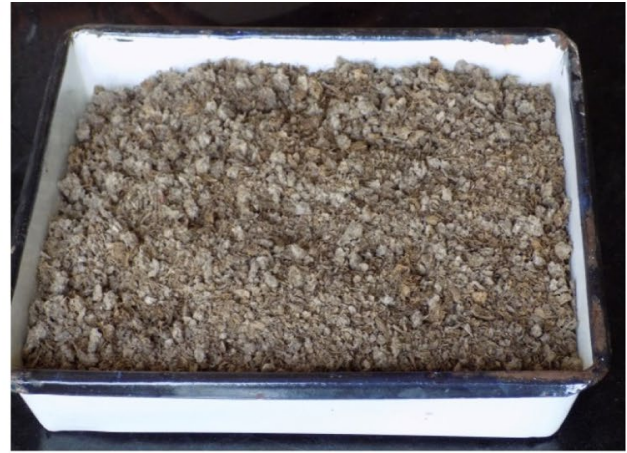

B
Table 3 Body weights (g) of broiler poultry fed with $5 \%$, $10 \%$ and $20 \%(w / w)$ fermented biomass

\begin{tabular}{|c|c|c|c|c|}
\hline \multirow[t]{2}{*}{ Age of birds } & \multicolumn{4}{|l|}{ Groups } \\
\hline & A & B & C & D (control) \\
\hline $24 \mathrm{~h}$ old & $37.8 \pm 2.09$ & $38.2 \pm 1.09$ & $37.8 \pm 2.09$ & $37.2 \pm 2.12$ \\
\hline 1st week & $150.5 \pm 3.14$ & $120.5 \pm 2.14$ & $150.5 \pm 3.14$ & $151.5 \pm 3.22$ \\
\hline 2nd week & $385.6 \pm 3.28$ & $312.6 \pm 3.18$ & $385.6 \pm 3.28$ & $395.6 \pm 4.21$ \\
\hline 3rd week & $751.3 \pm 4.23$ & $690.3 \pm 4.33$ & $751.3 \pm 4.23$ & $745.3 \pm 4.89$ \\
\hline 4th week & $1002 \pm 4.55$ & $1012 \pm 4.15$ & $1002 \pm 4.55$ & $1020.5 \pm 5.55$ \\
\hline 5th week & $1590.5 \pm 5.96$ & $1568.5 \pm 5.23$ & $1590.5 \pm 5.96$ & $1690.5 \pm 6.33$ \\
\hline 6th week & $1910.3 \pm 5.89$ & $1901.3 \pm 6.78$ & $1930.3 \pm 5.89$ & $1920.3 \pm 6.41$ \\
\hline
\end{tabular}

Values are means of three replicates \pm SD 
also found normal and it was consistent with the standard group (group D).

The feed consumption profile of the broiler chickens fed with $5 \%, 10 \%$ and $20 \%$ (wt/wt) of bioprocessed material is represented in Table 4. No significant difference was observed in feed consumption in the groups given different dietary treatment. Feed consumption was slightly decreased as the percentage of fermented biomass concentration is increased. The lowest feed consumption (3529.92 \pm 4.55$)$ was noticed when the finisher diet supplemented with $20 \%$ bioprocessed waste (Table 5). Moreover, the feed conversion rate was found to be improved when the animals were fed diets supplemented with $15 \%$ of bio-transformed agro-wastes. No significant difference was observed in the feed conversion rate of the test birds at the tested percentage.

\section{Discussion}

Use of cheaper agro-residues as a feedstuff in the poultry diet has the potential not only to support the poultry business economically but it will also enhance the environmental sustainability. A number of agro-wastes have been evaluated for their suitability as poultry feed with varying success [17]. Portsmouth et al. [18] obtained satisfactory growth of chickens fed on diets containing $2.5 \%$ feather meal but failed with 5\%, while Thomas et al. [19] obtained satisfactory performance with $7 \%$ feather meal. The processed material of groundnut in our study showed excellent palatability in broiler chickens. The proximate chemical analyses data reveals that the nutritive value of groundnut waste is improved after fermentation using Colletotrichum spp.

The mycelial growth and enzyme action during the SSF break down the complex polysaccharides into simple hexoses which are less complex structures and easily degradable [20]. Therefore, bioprocessed groundnut shells have improved the nutritional value of the test diet, suggesting that they can be potentially be used for supplementing the poultry feed.
Table 5 Feed conversion ratio of broiler fed with 5\%, 10\% and $20 \%$ (wt/wt) fermented biomass

\begin{tabular}{lllll}
\hline Age of birds & \multicolumn{3}{l}{ Groups } & \\
\cline { 2 - 5 } & A & B & C & D (control) \\
\hline 1st week & 1.09 & 1.09 & 1.07 & 1.07 \\
2nd week & 1.19 & 1.25 & 1.19 & 1.14 \\
3rd week & 1.40 & 1.49 & 1.38 & 1.44 \\
4th week & 1.67 & 1.61 & 1.56 & 1.63 \\
5th week & 1.89 & 1.83 & 1.78 & 1.77 \\
6th week & 1.98 & 1.95 & 1.89 & 2.60 \\
\hline
\end{tabular}

The crude protein content found to be doubled in the treated waste. The increase in crude protein may be due to release mycelial proteins of the fungi or the degradation of complex polysaccharides to form single cell protein (SCP) by the growing fungus during the fermentation process [21]. Secretion of extracellular enzymes such as pectinases, xylanases, cellulases and amylases by the fungus for utilization of the complex polysaccharides may responsible for increased protein content of the bioprocessed material [22-24]. The decrease in tannin and phytate content of the waste material may be due to phytase producing ability of the test fungi.

Total carbohydrates were also found to be increased indicating the release of hexoses as a function of production of extracellular protease by the Togninia spp. No significant decrease was reported in the tannins and phytate content in all three treated residues. The findings of the study demonstrated the economic and environmentally benign bioconversion of solid agro-residues into economically important products such as poultry feed using the endophytic microorganisms in SSF. Endophytic fungi used in the present study effectively transformed the cellulose and lignin-rich waste into simple hexoses. It appears that biological transformation of agro-waste using the endophytic fungi is economically feasible and can be easily adopted for bioconversion of agricultural wastes.

India is the agriculture based country where disposal of agro-wastes is the huge challenge. Thus, utilization of such
Table 4 Feed consumption of broiler fed with $5 \%, 10 \%$ and $20 \%(w / w)$ fermented biomass

\begin{tabular}{lrrrr}
\hline Age of birds & \multicolumn{3}{l}{ Groups } & \\
\cline { 2 - 5 } & A & \multicolumn{1}{l}{ B } & \multicolumn{1}{l}{ C } & D (control) \\
\hline 1st week & $181.23 \pm 3.47$ & $180.21 \pm 3.19$ & $179.37 \pm 2.81$ & $185.04 \pm 3.23$ \\
2nd week & $512.12 \pm 2.23$ & $520.06 \pm 3.55$ & $562.02 \pm 3.60$ & $538.35 \pm 3.17$ \\
3rd week & $1010.33 \pm 4.89$ & $1133.42 \pm 4.19$ & $1120.53 \pm 3.97$ & $1042.51 \pm 4.30$ \\
4th week & $1789.71 \pm 3.92$ & $1791.37 \pm 4.51$ & $1793.26 \pm 4.39$ & $1855.17 \pm 3.98$ \\
5th week & $2867.09 \pm 3.95$ & $2799.23 \pm 3.49$ & $2857.77 \pm 4.59$ & $2902.06 \pm 3.74$ \\
6th week & $3586.21 \pm 4.42$ & $3632.21 \pm 3.35$ & $3529.92 \pm 4.55$ & $3556.24 \pm 3.21$ \\
\hline
\end{tabular}

Values are the mean $\mathrm{SD} \pm$ of 10 observations 
waste by bioconversion can be a sustainable approach because the recycling and reduction of waste can reduce environmental pollution as well as it will reduce our dependence on conventional food grains as animal feedstuff. Although significant scientific work has been undertaken in this direction $[17,26]$ there have been no efforts made to develop and scale up the process for the production of valuable end products such as poultry feed using endophytic fungi. Findings of this study are a step forward in commercial exploration of endophytic fungi.

\section{Conclusions}

Fungal bioconversion of agro-residues improves their nutritional and energy profile. Both the endophytic fungi are able to transform the selected agro-residues into the digestible hexoses and significantly improved the protein and nitrogen content. The bio-transformed groundnut shell waste has highest total proteins, total carbohydrates, and digestible fats. Moreover, the phytate and tannin content was significantly lowered. Thus, the bioprocessed agro-residue using endophytic Colletotrichum spp. can be used as a partial substitute for energy and protein in poultry diet, especially in the countries where these products are grown and are widely available. The inclusion percentage of the supplement in this study will significantly reduce the use of conventional feed ingredients in poultry diet and ultimately reduce the cost of poultry diet. However, better understanding and more study on palatability, digestibility and feed intake are needed for increasing the inclusion percentage of bio-transformed waste into poultry diet is needed.

Acknowledgements This work was supported by the RGST\&C, Government of Maharashtra, India, managed by North Maharashtra University, Jalgaon. Authors acknowledge Mr. Manoj Chaudhari, Wathoda, Shirpur, India for his help in poultry trials.

\section{Compliance with ethical standards}

Conflict of interest The authors declare that they have no conflict of interest.

Ethical approval The experiments were carried out in compliance with the ethical and scientific standards for research on humans and animal subjects (Research Policy Document, UNN, 2017). All the methods were performed according to the guidelines of animal experimentation as approved by institutional animal ethics committee.

\section{References}

1. Basak B, Pramanik MA, Rahman MS, Tarafdar SU, Roy BC (2002) Azolla (Azolla pinnata) as a feed ingredient in broiler ration. Int J Poult Sci 1(1):29-34

SN Applied Sciences
2. Ravindran V (2013) Poultry feed availability and nutrition in developing countries. Poultry development review, pp 60-63

3. Mutucumarana RK, Ravindran V, Ravindran G, Cowieson AJ (2015) Measurement of true ileal phosphorus digestibility in maize and soybean meal for broiler chickens: comparison of two methodologies. Anim Feed Sci Technol 206:76-86

4. Abbott $P, D e$ Battisti $A B$ (2011) Recent global food price shocks: causes, consequences, and lessons for African governments and donors. J. Afr Econ 1(20):12-62

5. Ali MA, Leeson S (1995) The nutritive value of some indigenous Asian poultry feed ingredients. Anim Feed Sci Technol 55(3-4):227-237

6. Shehrawat PS, Sindhu N (2015) Agricultural waste utilization for a healthy environment and sustainable lifestyle. Ann Agric Biol Res 20:110-114

7. Bisaria R, Madan M, Bisaria VS (1987) Biological efficiency and nutritive value of Pleurotus sajor-caju cultivated on different agro-wastes. Biol Wastes 19(4):239-255

8. Patil RH, Patil MP, Maheshwari VL (2016). Bioactive secondary metabolites from endophytic fungi: a review of biotechnological production and their potential applications. In: Attaur-Rahman (ed) Studies in natural products chemistry, pp 189-205

9. Arnold AE, Maynard Z, Gilbert GS, Coley PD, Kursar TA (2000) Are tropical fungal endophytes hyperdiverse? Eco Lett 13(4):267-274

10. Makkar HP, Becker K (1999) Nutritional studies on rats and fish (carp Cyprinus carpio) fed diets containing unheated and heated Jatropha curcas meal of a non-toxic provenance. Plant Foods Hum Nutr 53(3):183-192

11. Wheeler EL, Ferrel RE (1971) A method for phytic acid determination in wheat and wheat fractions. Cereal Chem 48(3):312-320

12. Horwitz W (2000) Official methods of analysis of the AOAC International. In: The Association, vol 5, pp 23-56

13. Shieh TR, Ware JH (1996) Survey of microorganisms for the production of extracellular phytase. Appl Microbiol 16(9):1348-1351

14. Howson SJ, Davis RP (1983) Production of phytate-hydrolysing enzyme by some fungi. Enz Microb Technol 5(5):377-382

15. Doelle WH, Mitchel DA, Roltz CE (1992) Solid substrate cultivation, vol 5. Elsevier Applied Science, London, pp 7-16

16. Kumar D, Jain VK, Shanker G, Srivastava A (2003) Citric acid production by solid state fermentation using sugarcane bagasse. Process Biochem 38(12):1731-1738

17. Tiwari UP, Jha R (2016) Nutrient profile, and digestibility of tubers and agro-industrial coproducts determined using an in vitro model of swine. Anim Nutr 2(4):357-360

18. Portsmouth Jl, Cherry P, Sharman P (1999) The use of feather meal in practical broiler diets. In: 14th World Poultry Congress, Madrid, Spain, section, pp 631-652

19. Thomas OP, Bossard EH, Nicholson JL, Twining PV (1999) Use of feather meal in poultry diets. In: Md Univ Nutr Conf Feed Manufacturers Proc 23-33

20. Aderemi FA, Nworgu FC (2007) Nutritional status and root seriate biodegraded with Aspergillus niger. Am Eur J Agric Environ Sci 2(3):308-321

21. Iyayi EA (2004) Changes in the cellulose, sugar and crude protein contents of agro-industrial by-products fermented with Aspergillus niger, Aspergillus flavus and Penicillium sp. Afr J Biotechnol 3(3):186-194

22. Raimbault M (1998) General and microbiological aspects of solid substrate fermentation. Electron J Biotechnol 1(3):26-33

23. Oboh G, Akindahunsi AA, Oshodi AA (2002) Nutrient and antinutrient contents of Aspergillus niger-fermented cassava products (flour and gari). J Food Compos Anal 15(5):617-622 
24. Alimon AR (2011) Bioconversion and saccharification of some lignocellulosic wastes by Aspergillus oryzae ITCC-4857.01 for fermentable sugar production. Electron J Biotechnol 14(5):3-10

25. Huang C, Han L, Liu X, Ma L (2010) The rapid estimation of cellulose, hemicellulose, and lignin contents in rice straw by near infrared spectroscopy. Energy Sources Part A Recov Util Environ Eff 33(2):114-144

26. Kornegay ET, Potter LM, Ogunabameru BO, Welten MK, Wilson $\mathrm{JH}$, Potchanakorn M (1995) An evaluation of various response criteria in assessing biological availability of phosphorus for broilers. Poult Sci 74(11):1820-1830

Publisher's Note Springer Nature remains neutral with regard to jurisdictional claims in published maps and institutional affiliations. 